\title{
Tutorial
}

Lars Dick*, Stefan Risse and Andreas Tünnermann

\section{Process influences and correction possibilities for high precision injection molded freeform optics}

DOI 10.1515/aot-2016-0023

Received April 14, 2016; accepted May 24, 2016; previously published online June 30, 2016

\begin{abstract}
Modern injection molding processes offer a cost-efficient method for manufacturing high precision plastic optics for high volume applications. Besides form deviation of molded freeform optics, internal material stress is a relevant influencing factor for the functionality of a freeform optics in an optical system. This paper illustrates dominant influence parameters of an injection molding process relating to form deviation and internal material stress based on a freeform demonstrator geometry. Furthermore, a deterministic and efficient way for 3D mold correcting of systematic, asymmetrical shrinkage errors is shown to reach micrometer range shape accuracy at diameters up to $40 \mathrm{~mm}$. In a second case, a stressoptimized parameter combination using unusual molding conditions was 3D corrected to reach high precision and low stress freeform polymer optics.
\end{abstract}

Keywords: birefringence; freeform optics; injection molding; plastic optics; polymer; ultra-precision manufacturing.

\section{Introduction}

Modern optical systems applied to optical key markets such as mobile communication, healthcare, sensoric, security, lighting, and also photovoltaics need to have more complex optical surfaces to achieve enhanced

*Corresponding author: Lars Dick, JENOPTIK Healthcare and Industry, JENOPTIK Polymer Systems GmbH, Am Sandberg 2, 07819 Triptis, Germany, e-mail: lars.dick@jenoptik.com

Stefan Risse: Fraunhofer Institute for Applied Optics and Precision Engineering IOF, Albert-Einstein-Str. 7, 07745 Jena, Germany Andreas Tünnermann: Fraunhofer Institute for Applied Optics and Precision Engineering IOF, Albert-Einstein-Str. 7, 07745 Jena, Germany; and Friedrich-Schiller-Universität Jena, Abbe Center of Photonics, Institute of Applied Physics, Albert-Einstein-Str. 15, 07745 Jena, Germany

www.degruyter.com/aot

(C) 2016 THOSS Media and De Gruyter performance requirements, less components, and miniaturization. One possibility to achieve these challenging goals is the application of freeform components within the optical system. Currently, new mathematical approaches are under consideration [1] that allow for new optical designs without symmetry $[2,3]$. Products like headmounted displays (HMDs), head up displays (HUDs), detector elements, varifocal glasses, and innovative LED illumination optics require freeform optics to guarantee excellent function [4-7]. Especially for manufacturing of imaging optics, demands regarding a minimal form deviation are very high. Injection molding causes intrinsic stress in plastic optics. This effect has to be minimized for high precision, especially polarized light applications.

This paper explains the process-influencing parameters during injection molding with regard to form deviation and internal material stress based on systematically defined demonstrator geometry. As a result, molding parameter influences relating to these two quality parameters can be detected. Therefore, two process parameter combinations are defined as initial points to correct the form deviations at the mold: first to reach process stabilized form deviation and second for a minimized internal material stress. For each scenario, a developed 3D correction method was applied to minimize the form deviation up to a factor of 10 .

Replicated freeform optical elements usually generate an irregular thickness over the surface different from rotational symmetric lenses. Therefore, in most cases the main shrinkage in freeform optics will be non-symmetrical, too, especially in case of a significant asymmetric content. To compensate for such kind of non-uniform shrinkage, a new process chain is applied in this paper. As a result of the new process chain, a molded plastic freeform lens with accuracies of about $2 \mu \mathrm{m}$ over a diameter of $40 \mathrm{~mm}$ can be achieved as compared to about $20 \mu \mathrm{m}$ surface errors (state of the art) achieved in a conventional way [8]. So the form deviation was successfully improved from the typical range of illumination optics into the level of some imaging applications for molded plastic optics. In a second case, the internal stress was reduced to $25 \%$ by the use of unusual injection molding process parameters, in 
which large form deviation was compensated by a factor of 11 to about $10 \mu \mathrm{m}(\mathrm{P}-\mathrm{V})$ with the use of the developed 3D correction of the mold.

\section{Process elements and challenges for injection molding high precision freeform optics}

In general, the process chain for molding a freeform optical component is analogous to molding rotational symmetric optical elements. Within the process chain, design, material, mold, injection molding machine, automation, and quality assurance are fundamental determining factors with respect to the quality of molded optical components $[8,9]$.

The challenge in molding freeform optical elements is the compensation of the systematic shrinkage of the molding resin with regard to the optical lens surfaces. This compensation needs to be incorporated into the manufacturing of the mold inserts. The accurate measurement of the mold inserts as well as the lens optical surfaces in 3D is required.

With respect to the optical performance of plastic optics, properties of the raw material must be considered such as the molecular structure, the molecular conformation, and impurities. Today, the materials most commonly used for molding plastic optics are polymethyl methacrylate (PMMA), polycarbonate, polystyrene, cycloolefin polymer, and cycloolefin copolymer [9]. Besides molding of plastic optics, molding of glass is possible, too, while the process chain is different from the injection molding process due to other material properties of glass. Here, higher process temperatures, longer cycle times, and different mold materials have to be considered [10].

The basic elements within the process chain are the mold and the injection molding machine. In industry, different designs and types of injection molding tools and injection molding machines exist, cf. $[9,11]$.

After material preparation and mounting the injection molding tool onto the injection molding machine, the molding process can be started. Then the mold is closed, the polymer melt is filled, a compression phase is added, and a cooling phase follows. After that, the part can be ejected [9].

This paper focuses on the process influences with respect to form deviation and internal material stress by injection molding of freeform optics. For this kind of surface type, the mold insert is machined and corrected by the 'slow tool servo technology'. Ultra-precision tactile measurement and novel data handling methods are applied for process evaluation [12,13].

\section{Experimental process conditions}

\subsection{Demonstrator geometry}

For analyzing the injection molding process of freeform surfaces including novel correction strategies, an exemplary freeform surface has to be defined by a mathematic equation. Furthermore, the freeform optical surface has to be integrated into an optical volume element suitable for molding.

A continuous freeform with low frequency surface deviations of rotation symmetry is defined by equation (1) representing the sum of a non-rotational symmetric and a rotational symmetric part. In search of the freeform surface described, an exemplary Zernike polynomial function was defined applicable as beam shaping element [14].

$$
\begin{aligned}
& Z_{\text {freeform }}(x, y)=Z_{\text {nrs }}(x, y)+Z_{\mathrm{rs}}(x, y) \\
& =z_{\text {Zernike }}(4,4) \cdot \sqrt{10} \cdot\left(\frac{\sqrt{x^{2}+y^{2}}}{20}\right)^{4} \cdot \cos \left(4 \cdot \arctan \left(\frac{y}{x}\right)\right) \\
& +\frac{\frac{1}{R} \cdot\left(x^{2}+y^{2}\right)}{1+\sqrt{\left[1-\left(\frac{1}{R}\right)^{2} \cdot\left(x^{2}+y^{2}\right)\right]}}
\end{aligned}
$$

Within the Cartesian coordinates $(x, y, z), z$ is the sag at a defined $x-y$ position. The non-symmetrical term $\left(Z_{\text {nrs }}\right)$ is described by the $z_{\text {zernike }}(4,4)$ term with 0.2 , normalized to a radius of $20 \mathrm{~mm}$. The $z_{\text {zernike }}(4,4)$ term describes a socalled 'Tetrafoil' from the defined Zernike series. The rotational symmetric part $\left(Z_{\mathrm{rs}}\right)$ is a convex sphere with a radius $R$ of $100 \mathrm{~mm}$.

The deviation of the non-rotational symmetric part is $1.26 \mathrm{~mm}$ with a maximal slope of $18.4^{\circ}$ at the clear aperture diameter of $40 \mathrm{~mm}$. At the pitch circle in the outer area, three spherical elements with a radius of $10 \mathrm{~mm}$ are positioned that provide optional referencing of the freeform surface during measurement and in the optical system, respectively. The designed optical element has one such freeform surface; the second optical surface is flat.

The designed freeform surface has to be implemented into an optical volume element dedicated to the molding process. For this freeform lens, the gate position can be seen, and a bevel at the outer diameter was added for manufacturability. The outer diameter of the part is 70 


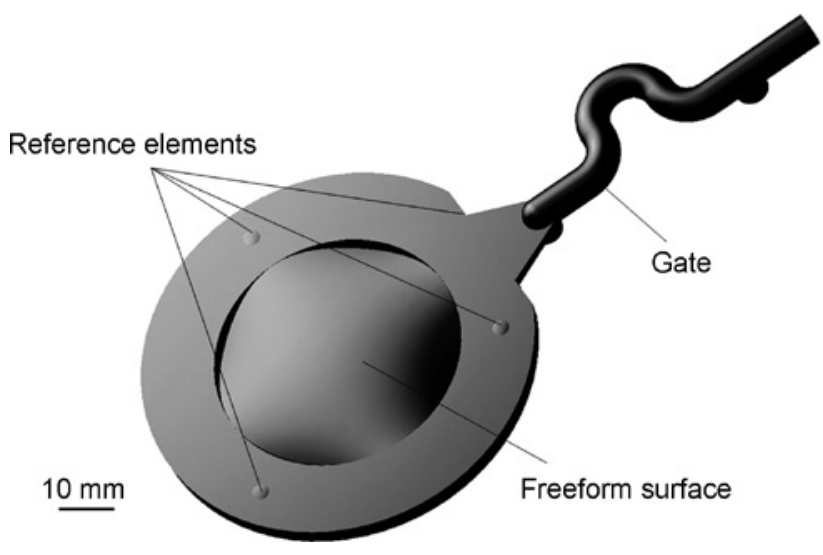

Figure 1: 3D CAD model of the demonstrator geometry.

$\mathrm{mm}$, and the center thickness is $5.5 \mathrm{~mm}$. The material of the lens is PMMA $7 \mathrm{~N}$. The three spherical reference elements can be used for alignment within measurement or system integration processes.

A 3D computer aided design (CAD) of the demonstrator geometry is shown in Figure 1.

\subsection{Mold manufacturing and 3D correction method}

Based on the design of the optical freeform element (Figure 1), the cavity as well as the complete injection mold was designed by 3D CAD software and manufactured. The classical configuration of a 3D CAD model with so-called nozzle and ejector side is shown in Figure 2 (left); the manufactured tool is given in Figure 2 (right). The optical tool inserts were realized with ultra-precision techniques (freeform insert, see Figure 3, middle). The non-optical elements were produced with classical tool shop methods like milling, turning, grinding, and electro discharge machining (sink and wire).

For manufacturing the freeform optical mold, ultraprecision machining methods utilizing a monocrystalline diamond tool are preferred for efficient machining [15]. The optical surface was designed for the slow tool servo technology. This process is qualified for generating smooth freeform surfaces where the two-axis diamond turning machine is modified with a computerized numerical control (CNC) controlled rotation $C$ axis in addition to the two linear axes ( $X$ and $Z$ ) [16]. The machine concept is shown in Figure 3 (left).

Understanding main error influences [13], the defined Zernike surface was manufactured at the mold according to the common procedure. The tool insert is a hardened steel substrate added with special nickel phosphorous plating. The machined mold insert was measured using the high accuracy profilometer Panasonic UA3P-5. The measurement accuracy for this kind of freeform surface (size, slopes) is better than $50 \mathrm{~nm}$ [17]. The measured surface data were subsequently evaluated by a best fit procedure. A surface accuracy with $2.27 \mu \mathrm{m} \mathrm{P}-\mathrm{V}$ and $0.375 \mu \mathrm{m}$ rms (root mean square), respectively, was measured at a clear aperture diameter of 40 $\mathrm{mm}$. Toachieve higher precision at themold freeform surface, a special iteration loop was developed. Fitting the deviation surface by a Fourier equation with a coefficient of determination $\mathrm{r}^{2}=0.99$ to the measured data, the deviation surface can be superimposed to Zernike surfaces in very high numerical precision. The Fourier function has an additional effect on smoothing the measurement data [8]. After calculating a tool path for correcting form deviation in the computeraided manufacturing (CAM) system, the freeform mold was machined. All technological process parameters have to be same.
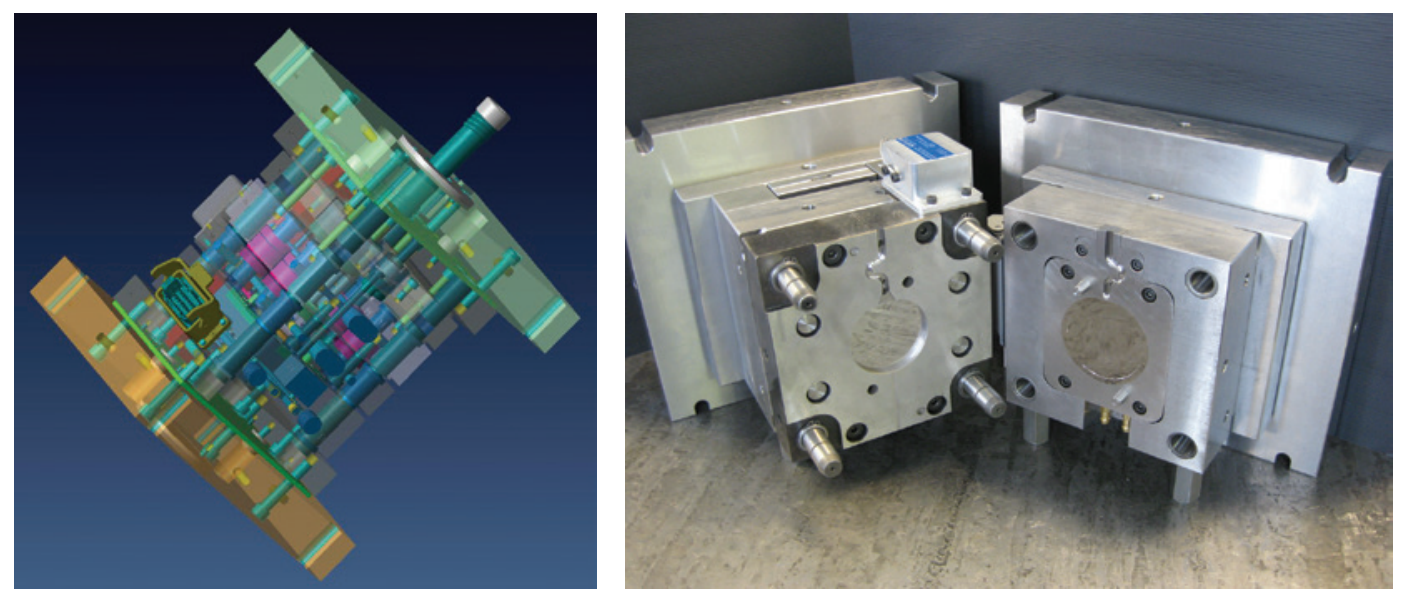

Figure 2: 3D CAD design of the mold tool (left) and manufactured mold tool (right). 

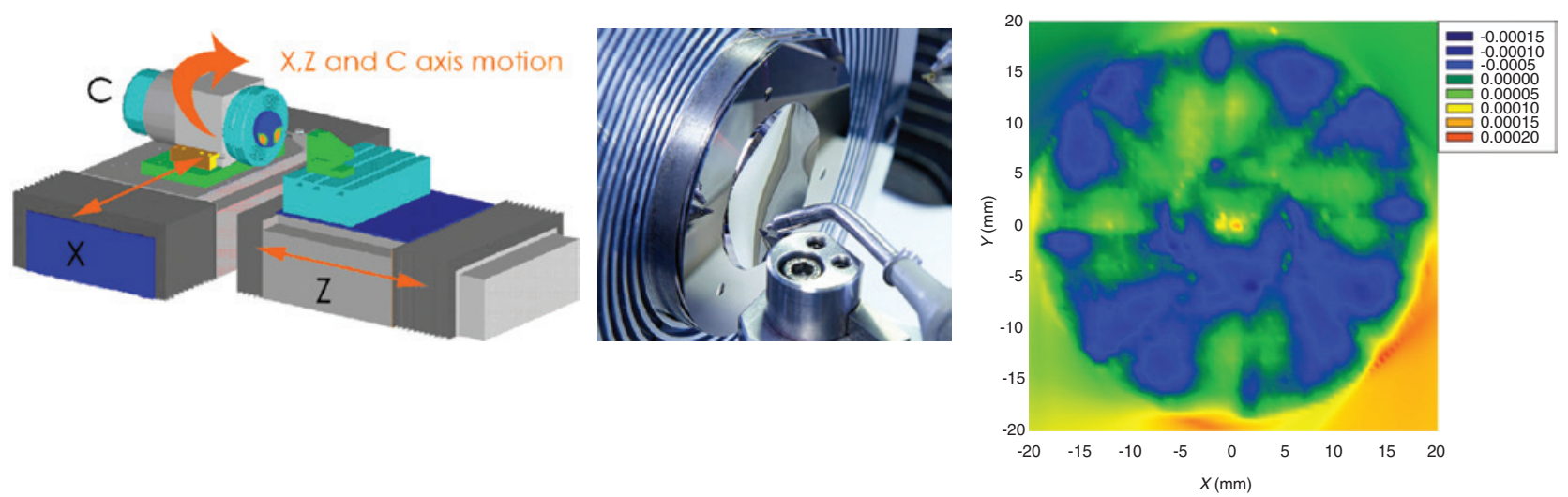

Figure 3: Machine concept and axes definition for slow tool servo technology [15] (left), freeform tool insert positioned at the vacuum chuck on the ultra-precision machine and diamond tool (middle), and surface deviation after one iteration loop, top view (right).

After one iteration loop, the form deviation was minimized from $2.27 \mu \mathrm{m}$ P-V $(0.375 \mu \mathrm{m}$ rms $)$ down to $0.24 \mu \mathrm{m}$ $\mathrm{P}-\mathrm{V}(33.1 \mathrm{~nm} \mathrm{rms})$, which is almost an order of magnitude (see Figure 3, right).

A comparable process chain was applied to compensate shrinkage of molded freeform optics, where additional coordinate transformations of the measured surface data have to be done to correct the shrinkage errors at the exact position.

\section{Process influences of the injection molding process regarding form deviation and internal material stress}

The quality of molded parts is a result of a complex combination of the used material (according to their pvT characteristics), the part and mold design as well as the process conditions. The resulting shrinkage and internal material stress are important factors affecting the quality of the molded part. Based on this physical relationship, the parameters melt temperature $T_{M}$, mold temperature $T_{\text {W }}$ dwell pressure $p_{N}$, dwell pressure time $t_{N}$, and cooling time $t_{r k}$ are analyzed as main influence parameters in this paper.

For molding the defined Zernike freeform optical volume element, the finished injection mold was mounted on the injection molding machine, where first processes were generated. First process parameters were defined with the help of material data (PMMA) and known values for such kind of geometries (thickness, size). These first process parameters resulted in a complete filled part of

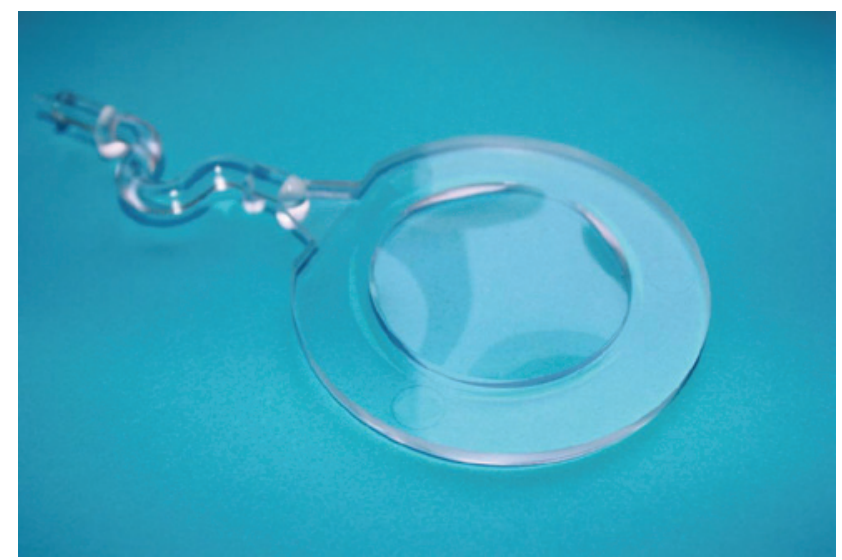

Figure 4: Molded freeform optical demonstrator including gate.

high quality, where typical specifications for high precision plastic optics (bubbles, inclusions, thermal damages, flow marks) were reached (see Figure 4).

For the analysis of form deviations in this chapter, a common 3D coordinate measurement machine was used, and results were calculated in the rms value as a reasonable overall surface quality value. For measuring the internal material stress, the optical path difference was evaluated in nanometers per centimeter by a polarimeter measuring system. Based on each five measurements, a scatter of these parameters was calculated, respectively.

\subsection{Influence parameter melt temperature}

The melt temperature was varied between $200^{\circ} \mathrm{C}$ and $280^{\circ} \mathrm{C}$. The process point at $280^{\circ} \mathrm{C}$ was defined by $20 \mathrm{~K}$ over the material reference point as usually optical 


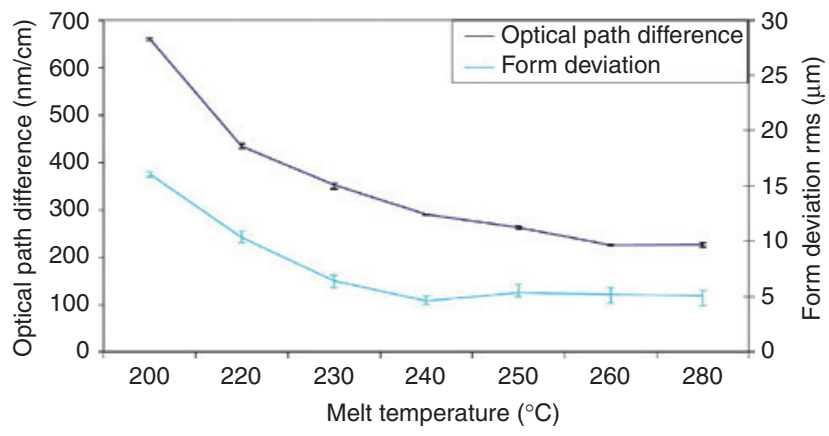

Figure 5: Connection between form deviation and optical path difference as a function of the melt temperature (constant process conditions: $\left.T_{w}=90^{\circ} \mathrm{C}, p_{N}=1000 \mathrm{bar}, t_{N}=30 \mathrm{~s}, t_{r k}=180 \mathrm{~s}\right)[8]$.

polymer parts are produced by applying the upper material limit $[18,19]$.

The result, a non-linear effect to both of the target parameters, can be seen in Figure 5.

An increased melt temperature results in a decreasing form deviation as well as optical path difference. The form deviation varies strongly under non-linear behavior between $16 \mu \mathrm{m}$ and $4.6 \mu \mathrm{m}$ (rms); the optical path difference varies at similar behavior between $660 \mathrm{~nm} / \mathrm{cm}$ and $226 \mathrm{~nm} / \mathrm{cm}$. A melt temperature above $240^{\circ} \mathrm{C}$ cannot show a further improvement of the form deviation. The internal material stress was influenced positively until $260^{\circ} \mathrm{C}$. At $280^{\circ} \mathrm{C}$ melt temperature, explicit surface defects were observed. Thus, this parameter might not be applied for optical parts.

A distinct correlation between varied melt temperature and process scatter of form deviation or optical tool path difference cannot be analyzed.

\subsection{Influence parameter mold temperature}

The mold temperature was varied between $67^{\circ} \mathrm{C}$ and $98^{\circ} \mathrm{C}$. The process point at $98^{\circ} \mathrm{C}$ was defined because of the relevance of the upper recommended mold temperatures by replicating polymer optics [18, 19]. The defined values were measured near the cavity with an accuracy of $\pm 1 \mathrm{~K}$. The results in Figure 6 show a significant non-linear effect of the mold temperature to the form deviation; an influence to the internal material stress cannot be derived. A mold temperature increasing to the upper level of the material specification of $90^{\circ} \mathrm{C}$ provides an improved form deviation of $4.6 \mu \mathrm{m}$ (rms) compared to $16 \mu \mathrm{m}$ (rms) at $67^{\circ} \mathrm{C}$ mold temperature. A further increase of the temperature to $98^{\circ} \mathrm{C}$ cannot provide further improvement of the form deviation. The optical path difference was very stable over the analyzed parameter variation at about $290 \mathrm{~nm} / \mathrm{cm}$.
A distinct correlation between varied mold temperature and process scatter cannot be analyzed based on the measurement results.

\subsection{Influence parameter dwell pressure}

A further experiment was carried out to identify the effect of the dwell pressure regarding form deviation and the internal material stress. For this, the dwell pressure was modified between 700 bar and 1400 bar. The resulting form deviation and optical path difference of the molded freeform optical polymer lenses is shown in Figure 7.

Both of the target parameters show a non-linear behavior by changing the dwell pressure. The form deviation decreases with a rising dwell pressure from $30 \mu \mathrm{m}$ down to $4.6 \mu \mathrm{m}$ (rms). The path difference rises from $130 \mathrm{~nm} / \mathrm{cm}$ to $330 \mathrm{~nm} / \mathrm{cm}$. Above $1000 \mathrm{bar}$, the negative influence to the internal material stress stabilizes, and a further improvement to the form deviation cannot be detected.

Obviously, the opposing trend of the two quality parameters appears. Applying as transmission optics,

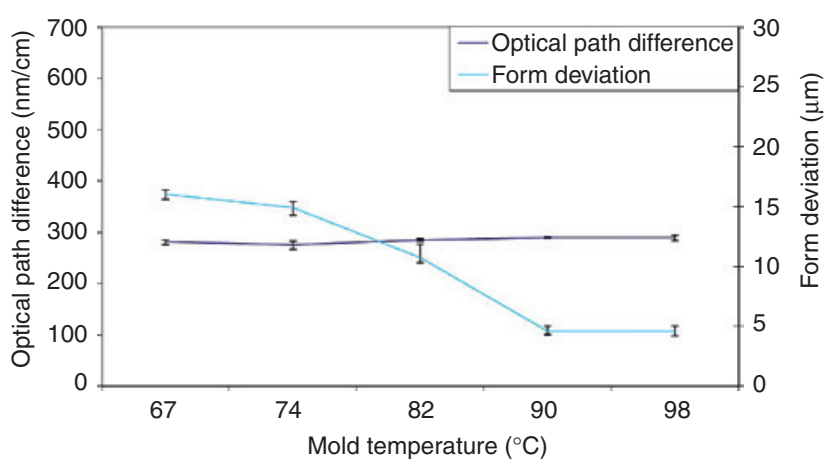

Figure 6: Connection between form deviation and optical path difference as a function of the mold temperature (constant process conditions: $T_{M}=240^{\circ} \mathrm{C}, p_{N}=1000 \mathrm{bar}, t_{N}=30 \mathrm{~s}, t_{r k}=180 \mathrm{~s}$ ) [8].

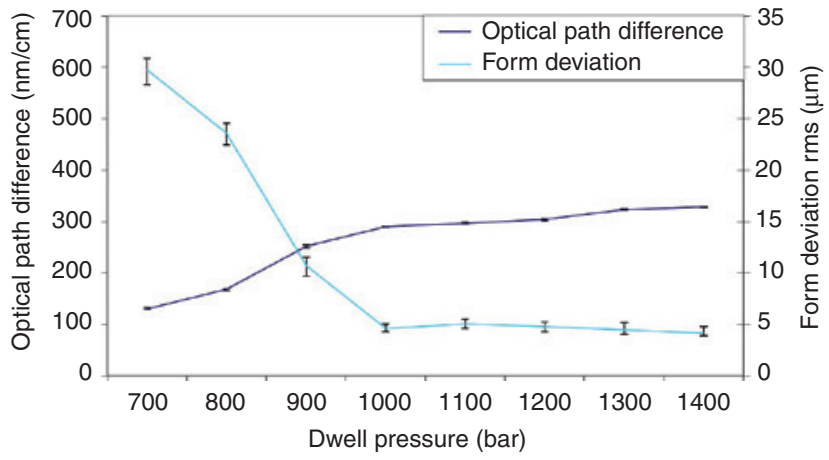

Figure 7: Connection between form deviation and optical path difference as a function of the dwell pressure (constant process conditions: $T_{W}=90^{\circ} \mathrm{C}, T_{M}=240^{\circ} \mathrm{C}, t_{N}=30 \mathrm{~s}, t_{r k}=180 \mathrm{~s}$ ) [8]. 
both of the parameters have to be minimal; a compromise between form deviation and internal material stress has to be found usually by determining the final process conditions. This situation can be relaxed by an extended process chain with 3D correction of the mold insert.

Another consequence of this experimental run is the resulting minimized process scatter of the form deviations after increasing dwell pressure (see error bar in Figure 7).

\subsection{Influence parameter dwell pressure time}

The dwell pressure time was varied between $10 \mathrm{~s}$ and $40 \mathrm{~s}$ due to the fact that 3D finite element method (FEM) simulations show a frozen sprue at $30 \mathrm{~s}$ dwell pressure time [20]. The effect of the variation with respect to form deviation and internal material stress is shown in Figure 8. An increasing dwell pressure time introduces a minimizing form deviation from $15.8 \mu \mathrm{m}$ to $4.4 \mu \mathrm{m}$ (rms), whereby a rising optical path difference from $217 \mathrm{~nm} / \mathrm{cm}$ to $290 \mathrm{~nm} / \mathrm{cm}$ can be observed. Over $30 \mathrm{~s}$ dwell pressure time, the influence of this effect stagnates on both parameters. The influence on the form deviation is caused by the shrinkage that can be compensated with more polymer melt by a longer dwell pressure time until the sprue is not frozen. The rising internal material stress results from the increased material pressure and difficult flow conditions within the freezing process. After $30 \mathrm{~s}$ dwell pressure time, the influence by the dwell pressure time stagnates because the gate is frozen, which is in good correlation to the 3D FEM simulations [20].

\subsection{Influence parameter cooling time}

The variation of the cooling time between $60 \mathrm{~s}$ and $240 \mathrm{~s}$ shows a comparatively slight influence on the form deviation and not measurable influence on the optical

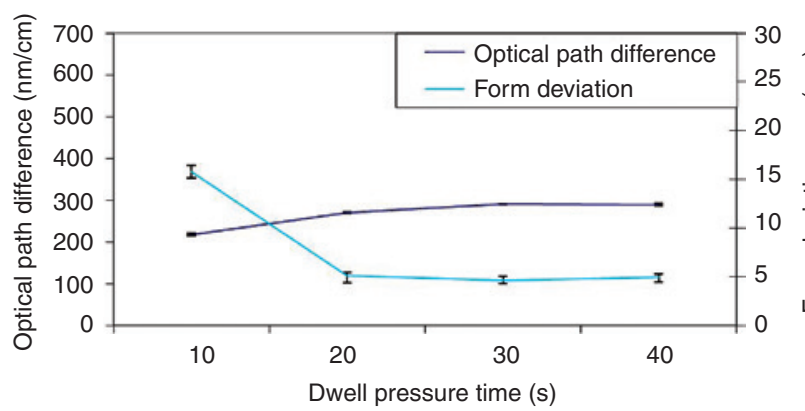

Figure 8: Connection between form deviation and optical path difference as a function of the dwell pressure time (constant process conditions: $T_{W}=90^{\circ} \mathrm{C}, T_{M}=240^{\circ} \mathrm{C}, p_{N}=1000 \mathrm{bar}, t_{r k}=180 \mathrm{~s}$ ) [8]. path difference; see Figure 9. A longer cooling time of $180 \mathrm{~s}$ provides a measured form deviation of $4.6 \mu \mathrm{m}$ (rms) compared to $8.6 \mu \mathrm{m}$ (rms) at $60 \mathrm{~s}$ cooling time. The reason can be found in a longer mold constraint at longer cooling times and, thereby, better cooling conditions. The internal material stress was evaluated by very constant values of the optical path difference of $290 \mathrm{~nm} / \mathrm{cm}$.

\section{Design of experiments (DOEs) in $3^{3}$ structure}

The main influence parameters with respect to the form deviation by injection molding of freeform optics are dwell pressure, melt temperature, and mold temperature. Dwell pressure and additional melt temperature have a significant influence on the optical path difference. To identify an interdependent influence between the parameters, a so-called $3^{3} \mathrm{DOE}$ (parameter field, see Table 1) was defined and operated within 27 subprocesses.

Each subprocess was evaluated at five molded parts. Besides the following measuring value (Figure 10, left), also the process scatter was measured (Figure 10, right). The results are shown at an optimal mold temperature of $90^{\circ} \mathrm{C}[8]$.

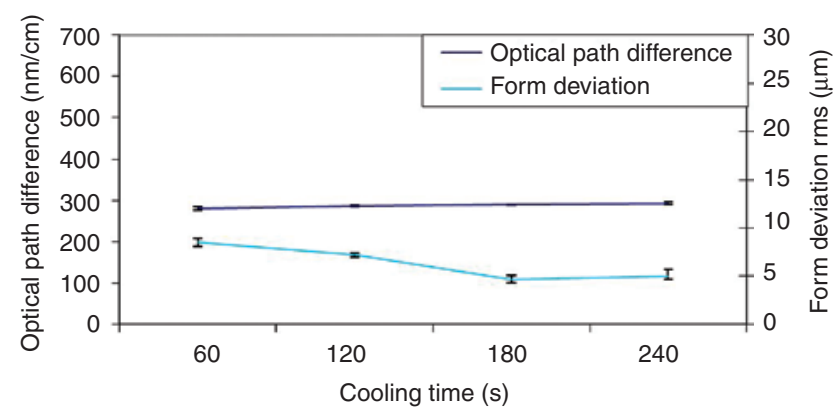

Figure 9: Connection between form deviation and optical path difference as a function of the cooling time (constant process conditions: $T_{W}=90^{\circ} \mathrm{C}, T_{M}=240^{\circ} \mathrm{C}, t_{N}=30 \mathrm{~s}, p_{N}=1000$ bar) [8].

Table 1: Varied parameters in the $3^{3} \mathrm{DOE}$.

\begin{tabular}{llllrr}
\hline Parameter & & & \multicolumn{2}{c}{ Parameter level } \\
\cline { 5 - 7 } Name & Unit & & L- & L0 & L+ \\
\hline Mold temperature & ${ }^{\circ} \mathrm{C}$ & & 74 & 82 & 90 \\
Melt temperature & ${ }^{\circ} \mathrm{C}$ & & 220 & 240 & 260 \\
Dwell pressure & $\mathrm{bar}$ & & 900 & 1000 & 1100 \\
\hline
\end{tabular}



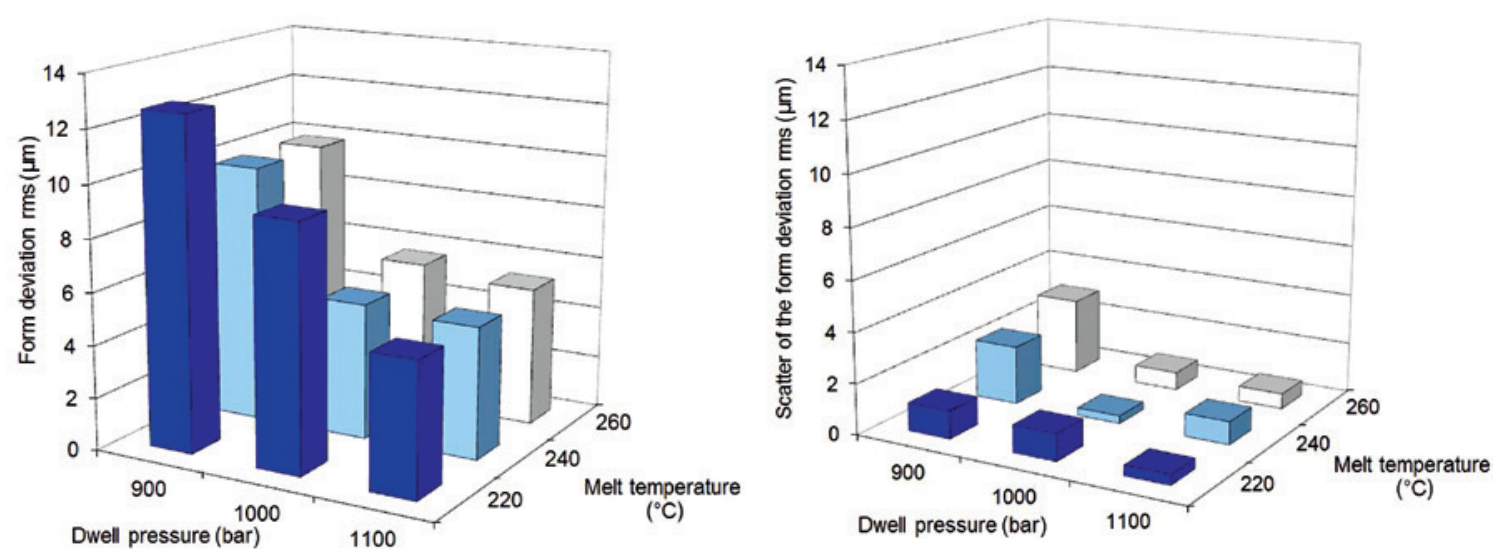

Figure 10: Connection between form deviation (left) and scattering (right) of the dwell pressure and melt temperature (constant process conditions: $\left.T_{w}=90^{\circ} \mathrm{C}, t_{N}=30 \mathrm{~s}\right)[8]$.

It can be seen that a rising dwell pressure as well as a rising melt temperature is optimizing the form deviation. The influence of the dwell pressure is more dominant in the analyzed field. A similar connection was analyzed at mold temperatures of $74^{\circ} \mathrm{C}$ and $82^{\circ} \mathrm{C}$. At $90^{\circ} \mathrm{C}$ mold temperature, a minimal form deviation was detected; therefore, this result is shown in detail.

The scattering of the measurement results varied between $6 \%$ and 30\% compared to the absolute values. Obviously, the scatter is higher at lower dwell pressure of 900 bar, which correlates with the result in Figure 7. The scatter at 1000 bar and 1100 bar is distributed more statistically. At 1000 bar dwell pressure, $240^{\circ} \mathrm{C}$ melt temperature, and $90^{\circ} \mathrm{C}$ mold temperature, a form deviation with a high systematic value is given by $5 \mu \mathrm{m}$ (rms) and a scatter of $0.3 \mu \mathrm{m}$ (rms). Further increasing dwell pressure and melt temperature cannot provide a further improvement of the form deviation and scatter. So this result will be the parameter combination to push the form deviation by the use of the 3D correction of the mold in the range of $0.3 \mu \mathrm{m}$ ( $\mathrm{rms}$ ).

The $3^{3}$ DOE was additionally evaluated regarding the internal material stress. Analyses revealed that melt temperature and dwell pressure have an influence to the optical path difference, whereas the melt temperature effect dominates in the reviewed process field. The mold temperature cannot show an effect to the optical path difference. So results at $90^{\circ} \mathrm{C}$ mold temperature are shown (see Figure 11), whereas best results regarding form deviation were found within the DOE design.

Within the DOE, a scatter of the optical path difference between $3 \mathrm{~nm} / \mathrm{cm}$ and $23 \mathrm{~nm} / \mathrm{cm}$ were detected at a stochastic connection. The lowest internal material stress was analyzed at 900 bar dwell pressure and $260^{\circ} \mathrm{C}$ melt temperature with $207 \mathrm{~nm} / \mathrm{cm}$ optical path difference. The maximal value was measured at $220^{\circ} \mathrm{C}$ melt temperature and 1100 bar dwell pressure with $455 \mathrm{~nm} / \mathrm{cm}$.
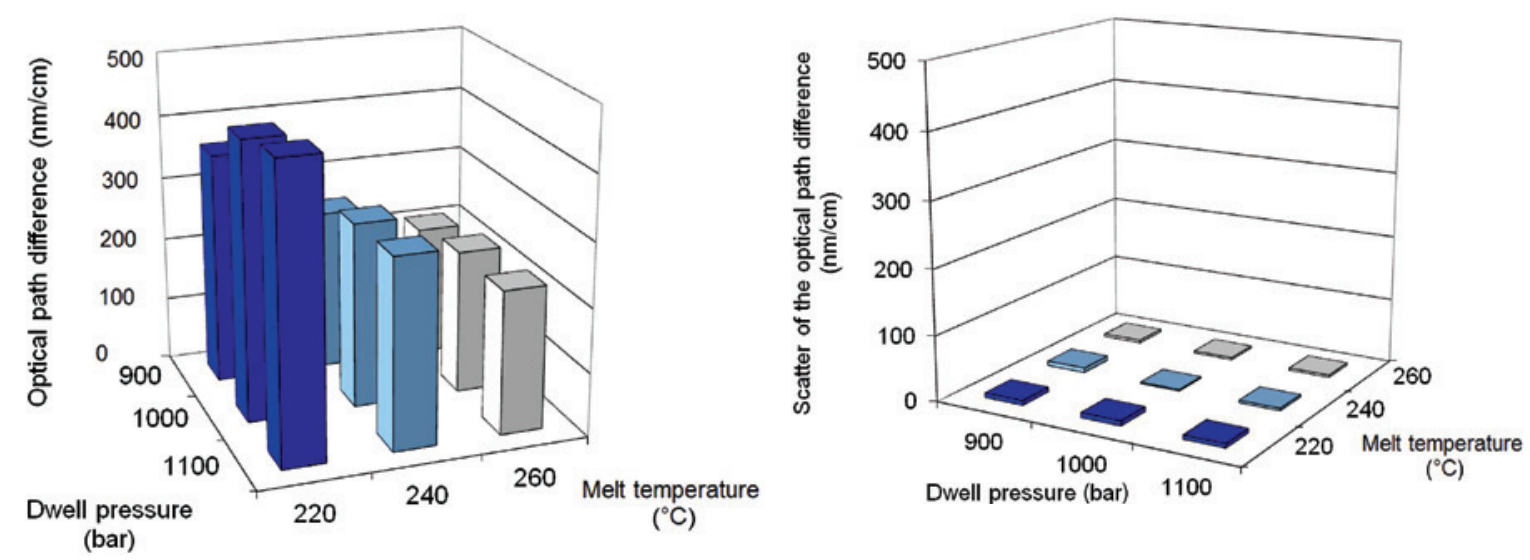

Figure 11: Connection between optical path difference (left) and scattering (right) of the dwell pressure and melt temperature (constant process conditions: $T_{W}=90^{\circ} \mathrm{C}, t_{N}=30 \mathrm{~s}$ ) [8]. 


\section{Correction possibility of the form deviation at different starting conditions}

\subsection{General process chain}

Based on results of Sections 4 and 5, the P-V values can be influenced up to given process limitations. To improve the precision of the defined freeform surface, further process steps are required; the measurement of the surface deviation at the molded part has to be described by a mathematical function. Then a freeform with corrected surface of the mold can be calculated, whereas the deviation of the molded freeform surface has to be superimposed to the sag of the optical design description at the tool insert. The new calculated surface comprises all information that controls the systematic shrinkage effect of the molding process. Before calculating the corrected surface for the tool insert, a transformation of the measured deviation surface with respect to the coordinate system of the mold has to be done. Transferring the point cloud with a raster size of $0.1 \mathrm{~mm} \times 0.1 \mathrm{~mm}$ to the CAM system as described in [13], the mold can be processed applying the modified tool path. Reference elements for the angle and the $x-y$ position for a high precision positioning of the mold are essential.

The main limitation of the process chain is the scatter of form deviation within the molding process. So the process parameter combination has to be defined based on a minimal variation to reach preferably best results regarding the form deviation after a 3D mold correction.

\subsection{Molding conditions with process stabilized form deviation}

A very stable parameter combination for molding the freeform demonstrator geometry was found at 1000 bar dwell pressure, $240^{\circ} \mathrm{C}$ melt temperature, and $90^{\circ} \mathrm{C}$ mold temperature. Using these parameters, a mean form deviation of $18.82 \mu \mathrm{m}(\mathrm{P}-\mathrm{V})$ and $4.38 \mu \mathrm{m}(\mathrm{rms})$ was reached at the molded freeform surface without 3D mold correction (Figure 12A). The systematic form deviation was characterized by a Fourier model with a coefficient of determination of 0.99 (Figure 12B). Middle and high frequency artifacts were filtered by using this mathematical model (Figure 12C). Using this model, a corrected freeform surface for the mold was calculated and machined. Molding the defined Zernike freeform optics again with the same molding process parameters but modified tool insert, the molded freeform lenses were measured. A form deviation of about $2 \mu \mathrm{m}(\mathrm{P}-\mathrm{V})$ and $0.28 \mu \mathrm{m}(\mathrm{rms})$ was reached by one iteration cycle, which is more than one order of magnitude better than without correction cycle. Results with $1.84 \mu \mathrm{m}$ (P-V) and $0.35 \mu \mathrm{m}$ (rms), respectively, are given in Figure 12D and $\mathrm{E}$. The character of the form deviation has a better symmetry compared to the character before correction (Figure 12A). Asymmetrical errors were highly reduced. The reproducibility with process break was evaluated with $2 \mu \mathrm{m}(\mathrm{P}-\mathrm{V})$ at existing experimental conditions. Process scattering is the main problem for a second iteration loop, whereas a systematic error surface is required. Random process variations cannot be corrected by this method.

\subsection{Molding conditions with minimized internal material stress}

Besides form deviations, internal material stress is an essential quality criterion for applications that use polarized light within transmission optics. Material stress introduces different densities per spatial directions and consequently a changing directional property of the refractive index, which accordingly becomes anisotropic. The internal material stress can be influenced by injection molding process parameters.

To find an optimal parameter combination with further reduced internal stress, another test run was done based on results shown. Here, the dwell pressure was further minimized at a maximum melt temperature of $260^{\circ} \mathrm{C}$ until a process with minimal internal stress and acceptable scatter of the form deviation was analyzed. The dwell pressure was varied between 100 bar and 700 bar. Up to 500 bar, molding volume was not completely filled as the parameter combination could not be used. At 700 bar dwell pressure, full volume molded freeform lenses were realized.

The internal material stress was evaluated by measuring the optical path difference. This difference was optimized from $290 \mathrm{~nm} / \mathrm{cm}$ to $66.5 \mathrm{~nm} / \mathrm{cm}$. Measurement results from the polarimeter are shown in Figure 13.

To evaluate the form deviation at modified injection molding conditions, samples were measured with a result of about $110 \mu \mathrm{m}(\mathrm{P}-\mathrm{V})$ and $31 \mu \mathrm{m}$ (rms); see Figure 14 (left). The process scatter was evaluated with $16 \mu \mathrm{m}(\mathrm{P}-\mathrm{V})$. The form deviation is by a factor 6 higher compared to the result at a melt temperature of $240^{\circ} \mathrm{C}$ and a dwell pressure of 1000 bar (optimal parameter values regarding form deviation). The character of the form deviation is a typical sink mark. After correcting the mold, the freeform lens was molded under constant process conditions. As result, a 

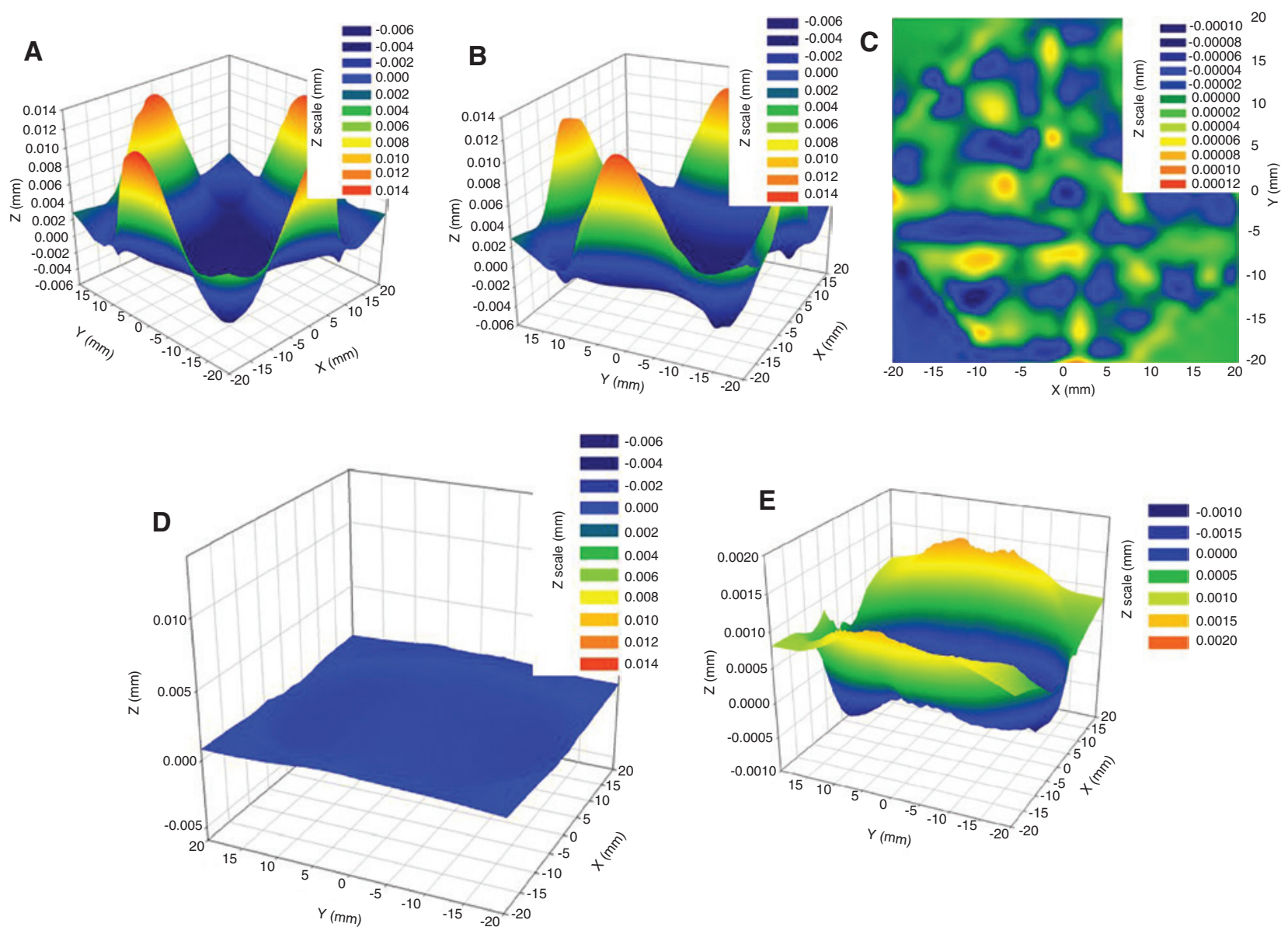

Figure 12: Mean form deviation (A), mathematical description (B), and mathematical accuracy (C) before local correction of the form deviation and corrected form deviation (exemplary) after one iteration cycle ( $D$ and $E$ ) [8].

(A) Form deviation before correction ( $P-V=18.82 \mu \mathrm{m} / \mathrm{rms}=4.38 \mu \mathrm{m})$. (B) Mathematical model for describing the form deviation before correction. (C) Difference between measured form deviation (A) and mathematical model (B) aligned scale. (D) Exemplary form deviation after one iteration loop $(\mathrm{P}-\mathrm{V}=1.84 \mu \mathrm{m} / \mathrm{rms}=0.35 \mu \mathrm{m})$. (E) Exemplary form deviation after one iteration loop $(\mathrm{P}-\mathrm{V}=1.84 \mu \mathrm{m} / \mathrm{rms}=0.35 \mu \mathrm{m})$ aligned scale.
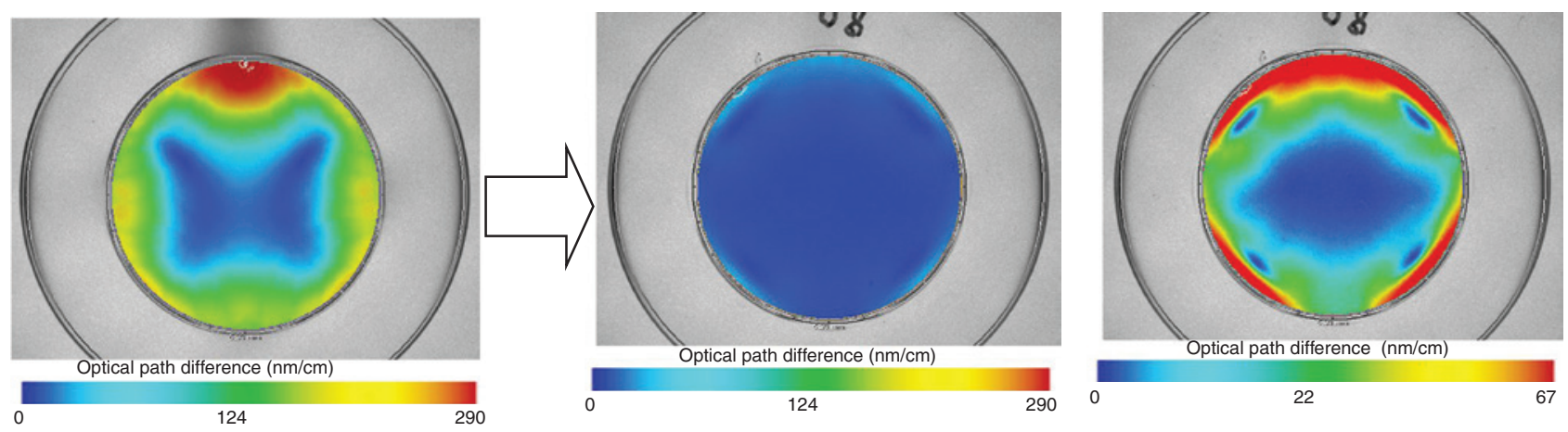

Figure 13: Optical path difference of a replicated lens without (left) and with (middle and right) optimized molding parameters (constant process conditions: $T_{W}=90^{\circ} \mathrm{C}, T_{M}=240^{\circ} \mathrm{C}, t_{r k}=180 \mathrm{~s}$ ) [8].

Left: Optical path difference before parameter optimization: $290 \mathrm{~nm} / \mathrm{cm}\left(p_{N}=1000\right.$ bar, $\left.T_{M}=240^{\circ} \mathrm{C}\right)$. Middle: Optical path difference after parameter optimization: $66.5 \mathrm{~nm} / \mathrm{cm}\left(p_{N}=700 \mathrm{bar}, T_{M}=260^{\circ} \mathrm{C}\right)$. Right: Optical path difference after parameter optimization: $66.5 \mathrm{~nm} / \mathrm{cm}$, aligned scale) $\left(p_{N}=700\right.$ bar, $\left.T_{M}=260^{\circ} \mathrm{C}\right)$. 

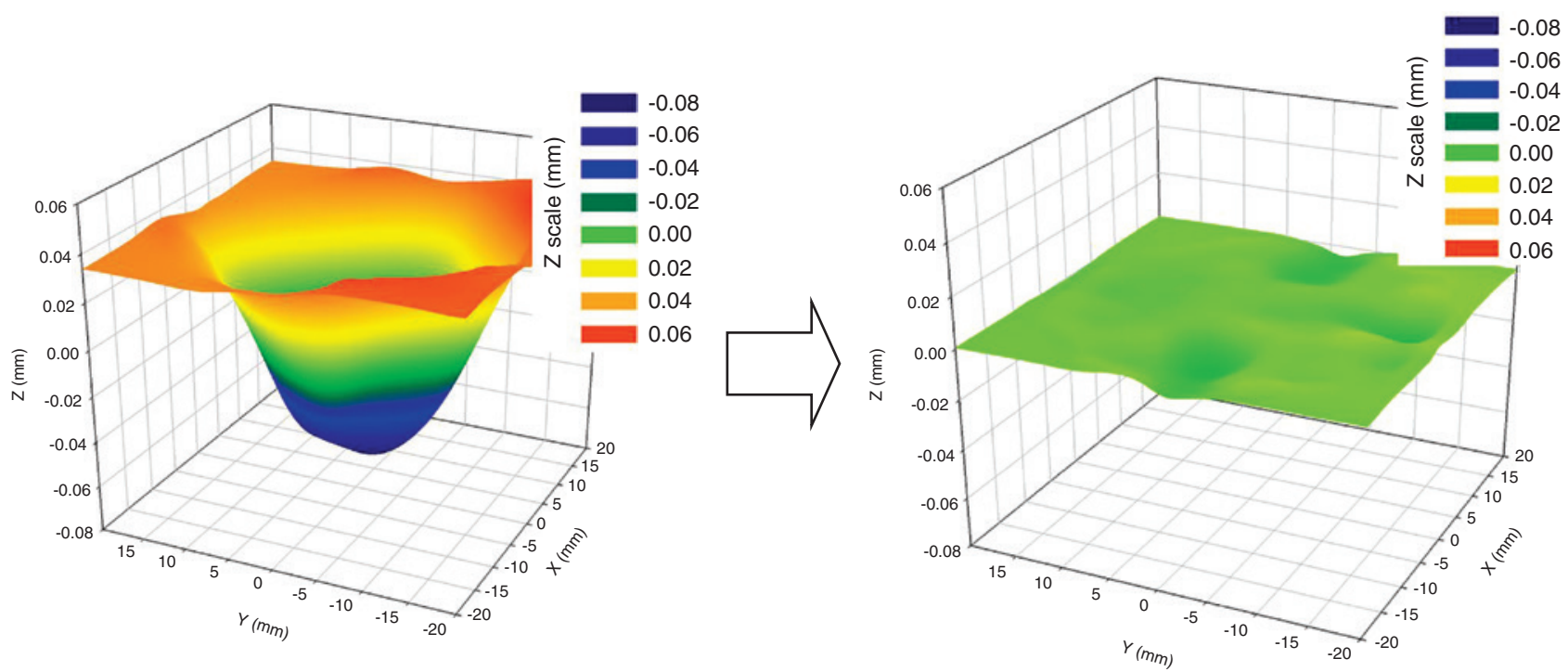

Figure 14: Form deviation of a molded freeform surface with optimized molding parameters to minimize internal material stress before (left: $\mathrm{P}-\mathrm{V}=108.8 \mu \mathrm{m} / \mathrm{rms}=30.9 \mu \mathrm{m}$ ) and after mold correction (right: $\mathrm{P}-\mathrm{V}=10.7 \mu \mathrm{m} / \mathrm{rms}=1.9 \mu \mathrm{m}$ ) [8].

reduction of the form deviation by factor 10 to about $11 \mu \mathrm{m}$ (P-V) and $1.9 \mu \mathrm{m}(\mathrm{rms})$, respectively, was reached (Figure 14, right). A further iteration loop is not recommended as the process scatter of the form deviation is limiting further success by applying the process chain for mold correction.

The results show that internal material properties can be improved by applying unusual injection molding process parameters, if the form deviation can be corrected by the novel method for 3D mold correction. Thus, both the internal material stress and the form deviation can be optimized combining the use of standard parameters within the injection molding process.

\section{Conclusions}

Process influences at injection molding of freeform optics regarding form deviation and internal material stress are discussed. Based on a DOE, two relevant start conditions were defined. A 3D mold correction method was developed and applied to each of the conditions.

Obtained manufacturing accuracies prove that a deterministic process chain was realized, which allows manufacturing of novel high precision freeform optics for high volume applications. The form deviation was improved from the typical range of illumination optics into the level of some imaging applications like HUDs or HMDs in high volume.

As a result, asymmetrical shape deviations have been minimized to about $2 \mu \mathrm{m}$ at the molded freeform surface with $40 \mathrm{~mm}$ in diameter using stabilized process parameters with respect to the process scatter of the form deviation at the molded lenses. Secondly, the internal material stress was reduced by factor 6 under the use of unusual parameter combinations. The resulting form deviation was optimized by factor of 10 to about $11 \mu \mathrm{m}$ (P-V) using a 3D mold correction procedure.

Acknowledgments: Main elements of the presented research work are funded by the Federal Ministry for Education and Research within the project FREE (Grant No. JENOPTIK Polymer Systems GmbH: 13N10826, Grant No. Fraunhofer IOF 13N10827). The authors are very thankful for such a possibility for efficient research.

\section{References}

[1] D. Michaelis, P. Schreiber and A. Bräuer, Opt. Lett. 36, 918-920 (2011).

[2] S. Zwick, P. Kühmstedt, G. Notni. Proc. SPIE 8169, 33 (2011).

[3] L. Li and A. Y. Yi, J. Opt. Soc. Am. 27, 2613-2620 (2010).

[4] H. Ries and J. Muschaweck, J. Opt. Soc. Am. 19, 590-593 (2002).

[5] S. Riehemann, M. Palme, R. Steinkopf, P. Munzert, G. Notni, et al., in 'Monolithisches optisches Freiformelement für eine IR-Detektorzeile', (DGAO Tagung IImenau, 2011).

[6] R. Eberhardt, in 'Freiformoptik-Die Herausforderung für zukünftige optische Systeme', (Laser+Photonik, 2010) pp. 38-39.

[7] P. Ott, Proc. SPIE 7100, 71000Y (2008).

[8] L. Dick, Spritzgießen hochpräziser freiformoptischer Komponenten, Jena, PhD thesis, Friedrich Schiller Universität, 2014. 
[9] S. Bäumer, in 'Handbook of Plastic Optics', Second Edition (Wiley-VCH - Verlag, 2010), pp. 39-47, 56, 64, 199-201.

[10] M. Hünten, F. Klocke and O. Dambon, Proc. SPIE 7591, 75910X (2010).

[11] M. P. Schaub, in 'The Design of Plastic Optical Systems' (SPIE Press, Bellingham, Washington, USA, 2009), pp. 47-55, 84.

[12] R. Steinkopf, S. Scheiding, A. Gebhardt, S. Risse, R. Eberhardt, et al., Proc. SPIE 81690X-9 (2011).

[13] L. Dick, S. Risse and A. Tünnermann, in 'Injection Molded High Precision Freeform Optics For High Volume Applications' (Advanced Optical Technologies, Vol. 1, De Gruyter Verlag, 2012), pp. 31-37.

[14] L. Dick, in 'High Precision Freeform Polymer Optics' (Optik+Photonik, Wiley-VCH Verlag, 2012), pp.33-37.

[15] R. Steinkopf, A. Gebhardt, S. Scheiding, M. Rohde, O. Stenzel, et al. in Proc. SPIE 7102, 71020C (2008).

[16] K. Rogers and J. Roblee, in 'Freeform Machining with Precitech Servo Tool Options', www.ametek.com, download 2010.

[17] web: http://industrial.panasonic.com, 16.12.2011.

[18] S. Böllinger, Spritzgießen und Spritzprägen von Kunststoffoptiken, Aachen, PhD thesis, RWTH Aachen, 2001.

[19] R. U. Müller, in 'Anforderungen an Maschinen und Anlagentechnik zur Fertigung hochpräziser Kunststoffoptiken'. 3. Fachkonferenz Kunststoffe in Optischen Systemen, Baden Baden (2012).

[20] L. Dick and L. Florez, in 'Virtual Mold Trials: Shortcut on the Way to Freeform Optics' (Kunststoffe international, Hanser Verlag, 2013).

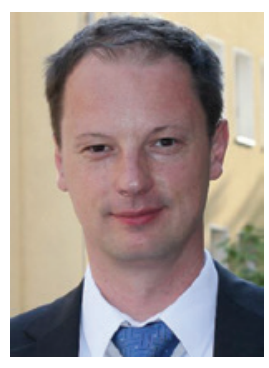

\section{Lars Dick}

JENOPTIK Healthcare and Industry, JENOPTIK Polymer Systems GmbH, Am Sandberg 2 07819 Triptis, Germany lars.dick@jenoptik.com

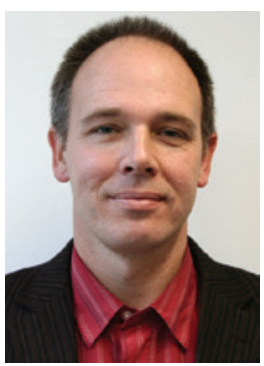

Stefan Risse

Fraunhofer Institute for Applied Optics and Precision Engineering IOF, Albert-EinsteinStr. 7, 07745 Jena, Germany

Stefan Risse was born in Jena, Germany, on April 27, 1964. He received the diploma degree in Mechanical Engineering from the Technical College Zittau in 1990 and the Dr.-Ing. degree in Precision Engineering from the Technische Universität Ilmenau in 2001. From 1990 to 1991, he worked at the Friedrich Schiller Universität Jena in the field of material science. He joined the Fraunhofer Institute for Applied Optics and Precision Engineering IOF in Jena in 1992. Since 1995, he is the head of Precision Systems group at Fraunhofer IOF.

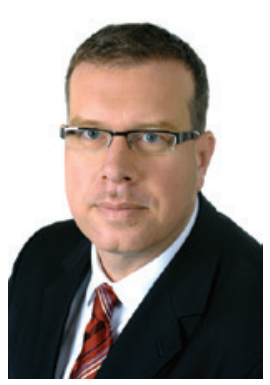

\section{Andreas Tünnermann}

Fraunhofer Institute for Applied Optics and Precision Engineering IOF, Albert-EinsteinStr. 7, 07745 Jena, Germany; and FriedrichSchiller-Universität Jena, Abbe Center of Photonics, Institute of Applied Physics Albert-Einstein-Str. 15, 07745 Jena, Germany

Andreas Tünnermann was born in Ahnsen, Germany, on June 10, 1963. He received the diploma and $\mathrm{PhD}$ degrees in physics from the University of Hannover in 1988 and 1992, respectively. In 1997, he received the habilitation. He was head of the department of development at the Laser Zentrum Hannover from 1992 to 1997. In the beginning of 1998, he joined the Friedrich-Schiller-Universität Jena, Germany, as a professor and director of the Institute of Applied Physics. In 2003, he additionally became the director of the Fraunhofer Institute for Applied Optics and Precision Engineering IOF in Jena. He is a sought-after expert in optics and photonics industry. $\mathrm{He}$ is founder and member of the board of directors of the industry driven cluster OptoNet e.V. Jena, one of the most dynamic regional optics clusters in Europe. Andreas Tünnermann is a member of various societies, e.g. of the German Physical Society and the Optical Society of America. His research activities on applied quantum electronics have been awarded e.g. with the GottfriedWilhelm-Leibniz-Award (2005) and the ERC - Advanced Grant (2015).
Lars Dick was born in Jena, Germany, on November 11, 1982. He graduated in mechanical engineering from 2002 to 2007 focusing on optics and precision engineering at the Technische Universität Ilmenau, where he received his diploma degree. In 2014, he reached the Dr.-Ing. degree from the Friedrich Schiller Universität Jena. He is head of the Ultra Precision Technology group at the JENOPTIK Polymer Systems GmbH since 2008 and, additionally, the head of the coating group since 2013. The research interests include diamond machining, replication techniques, coating, and metrology of optical surfaces. 